\title{
A Research on English Teachers' Perception of English Listening by Analysis of a Questionnaire
}

\author{
HU Yan \\ Shanghai Institute of Technology, Shanghai, China
}

\begin{abstract}
Among the four skills of English learning — reading, writing, listening, and speaking, listening is always considered as the most implicit skill to teach, which makes it the most demanding course for English teachers in China. This study is to investigate the teachers' understanding of listening and listening teaching, thus to provide useful date on how to conduct the class teaching to fulfill teaching purpose. By analyzing the results from a questionnaire on 78 English teachers in three different colleges, the author made a conclusion that most teachers realized the importance of English listening, yet they failed to use the effective methods in class teaching.
\end{abstract}

Keywords: English listening, teaching methods, class teaching

\section{Introduction}

As many teachers, researchers, and linguists have frequently noted, listening is primary in all learning, in that it comes before speaking, reading, and writing in the development of all communications skills (Mendelsohn, 1998). However, as the least explicit course, listening is a crux of matter in learning and teaching, thus making itself a course demanding high teaching techniques of teachers. So, as English teachers, our primary task in teaching listening is to make clear which are effective methods to help students in listening. But in the reality many English teachers are at a loss in finding out what are the effective strategies. To get data on teachers' understanding of listening procedure and teaching methods, the author conducted a questionnaire on 78 English teachers in three different colleges of China, trying to find out whether the English teachers recognize the importance of listening, and which method they use in teaching practice.

\section{Design of the Study}

The questionnaire includes four parts. Part one is about some factual information for teachers, such as age, gender, especially the time for English teaching. Part two is about the teacher's understanding of what the listening is (from mainly four perspectives). Part three is about the teacher's conception of what difficulties students may have and the selection of listening materials. Part four is about the activities the teacher uses in class teaching.

To design the questions concerning about teachers' understanding on listening, I mainly refer to the Rost's clarifications of listening (Rost, 2005). In his book Teaching and Researching Listening, Rost concludes four orientations which some unique definitions of listening are draw upon: receptive (receiving what the speaker actually says); constructive (constructing and representing meaning); collaborative (negotiating meaning with

HU Yan, associate professor, master, Department of Foreign Language, Shanghai Institute of Technology. 
the speaker and responding); and transformative (creating meaning through involvement, imagination, and empathy).

The study was carried out in three different colleges located in two different cities, two in shanghai, and one in Hunan. The participants are English teachers from the following three colleges: Hunan Xiangtan University (a comprehensive university), Shanghai Institute of Foreign Trade (a college with emphasis on foreign language and trade), and Shanghai Institute of Technology (a college with emphasis on applied science). With participants up to 78, this paper justifies its data validity in sense of wild range of participants (numbers and different backgrounds of participants).

\section{Data Analysis}

This section focuses on the detailed analysis of the results of the questionnaire, which is presented in the form of tables or bars. The first part is about the general information of the participants, gender, the time of teaching, major of their students, etc. Questions 2 to 4 try to investigate their understanding of what listening is and how important listening is. Question 5 tries to investigate teachers' recognition of what difficulties students have in listening learning. Questions 6 to 7 try to investigate the materials teachers adopt in class teaching. Questions 8 to 12 try to investigate which activities teachers conduct in class teaching. Question 13 tries to investigate degree of students' cooperation. Questions 14 to 15 try to investigate information about homework. The detailed analysis is given as follows.

\section{First Part: General Information}

In the first part, the participants are asked to fill in with their personal information as gender, time of teaching English, and major of their students.

Table 1

The Results of General Information

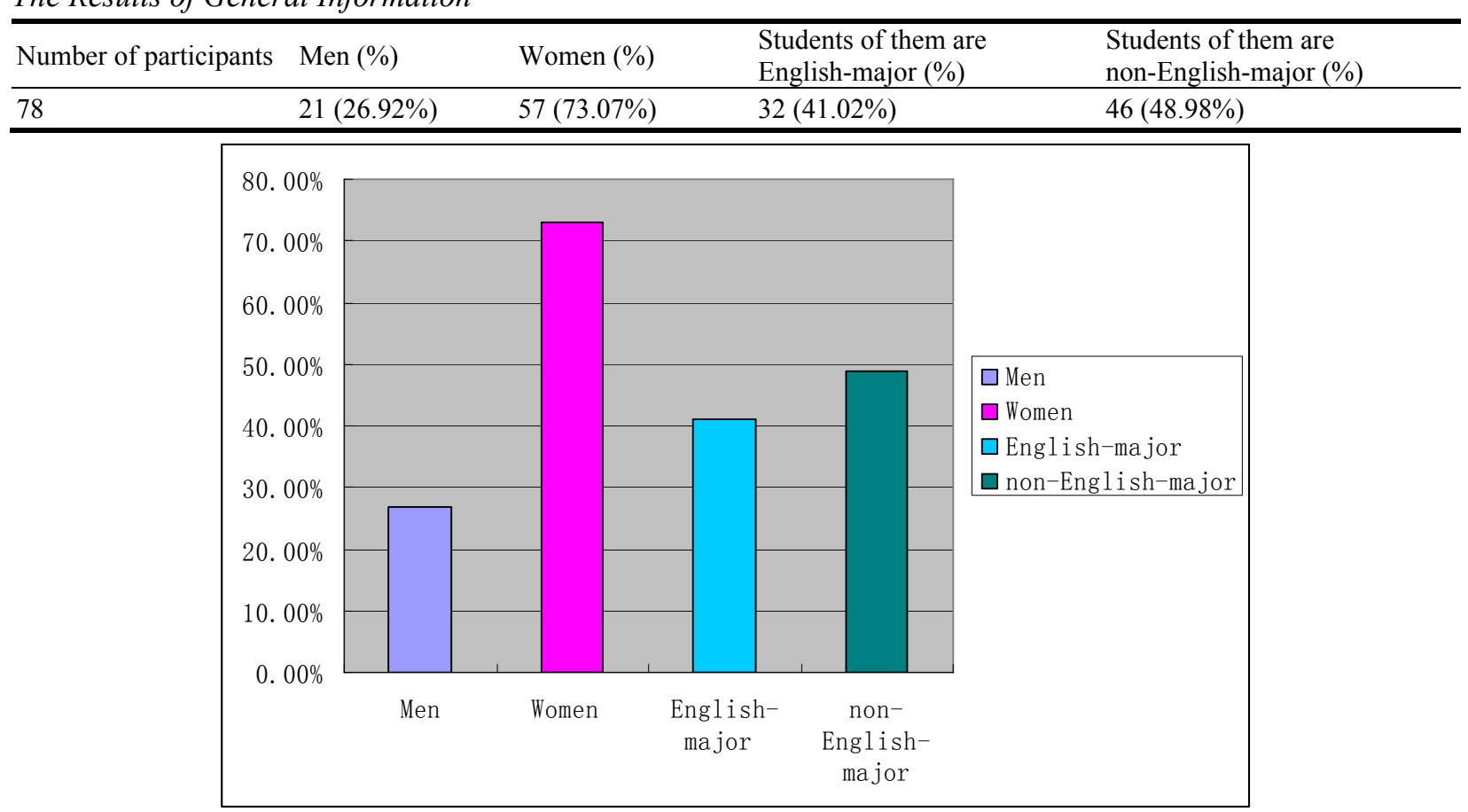

Figure 1. The results of general information. 
Table 2

Results About Participants When Time of Teaching Is Concerned

\begin{tabular}{lllll}
\hline Number of participants & $1-5$ years & $6-10$ year & $11-15$ years & More than 15 years \\
\hline 78 & $20(25.64 \%)$ & $22(28.61 \%)$ & $21(26.92 \%)$ & $15(19.23 \%)$ \\
\hline
\end{tabular}

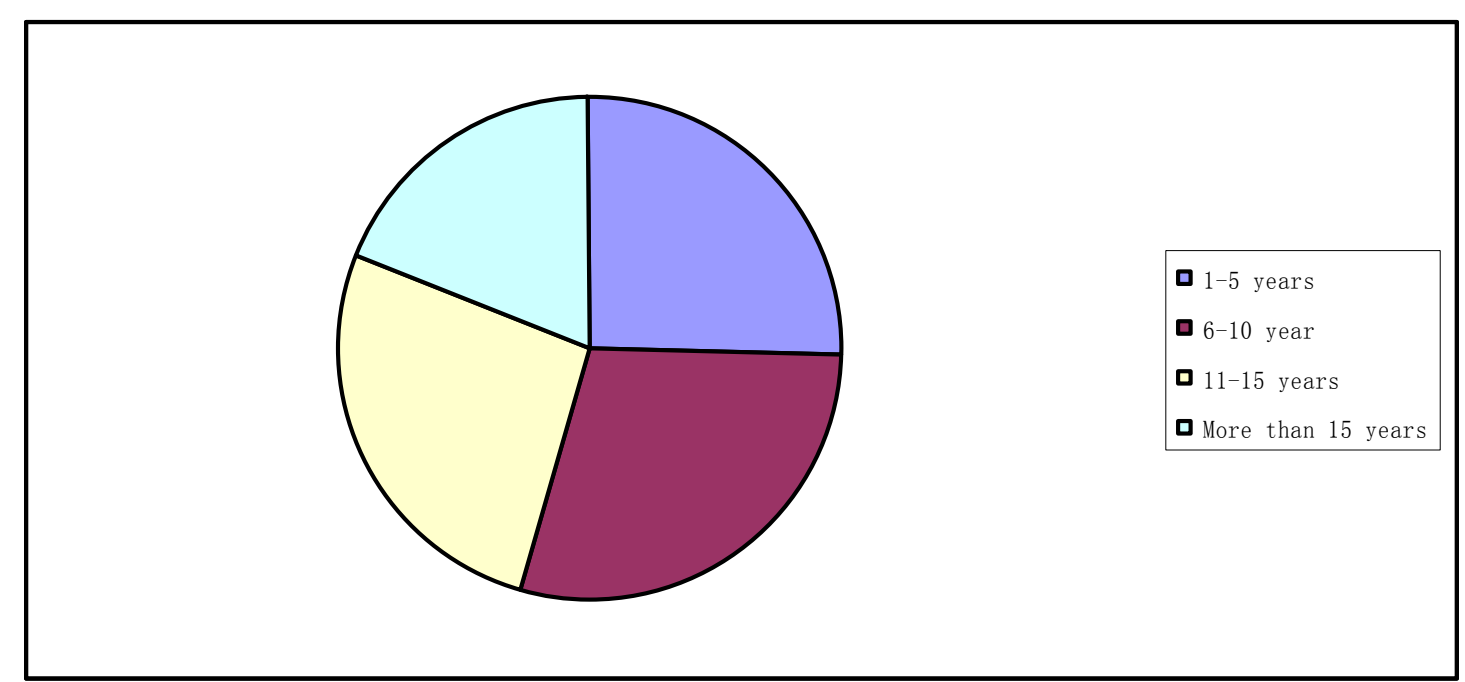

Figure 2. The results of Table 2 in bar graph.

Result description: From Table 1 and Figure 1, we can see clearly that numbers of female teachers are much more than male teachers, which accords with the reality in college English teaching; however, it may affect the conclusion of the study. The numbers of English-major and non-English-major students are not equal, which will not affect the conclusion. From Table 2 and Figure 2, we can see that the numbers from four ranges of age are almost the same, thus guaranteeing the validity of data.

\section{Question 2 to Question 5}

Question 2 is to investigate the teachers understanding of what is listening; the choices to this question are designed from four perspectives according to Rost (2005, pp. 2-3). From a receptive perspective, listening means catching what the speaker has said (choice of A) and receiving the transfer of image, impressions, thought, beliefs, attitudes, and emotions from the speaker (choice of B). From a constructive perspective, listening means figuring out what is in the speaker's mind (choice of $\mathrm{C}$ ) and reframing the speaker's message in a way that is relevant to you (choice of D). From a collaborative perspective, listening is coordination with the speaker on the choice of a code and a context (choice of $\mathrm{E}$ ) and the process of negotiating shared information or values with the speaker (choice of F). From a transformative perspective, listening is creating meaning through involvement, imagination, and empathy (choice of $\mathrm{H}$ ), and creating a connection between the speaker and the listener (choice of G).

Table 3

Results of Question 2

\begin{tabular}{|c|c|c|c|c|c|c|c|c|}
\hline \multirow{2}{*}{$\begin{array}{l}\text { Perspective } \\
\text { Choice }\end{array}$} & \multicolumn{2}{|c|}{ Receptive } & \multicolumn{2}{|c|}{ Constructive } & \multicolumn{2}{|c|}{ Collaborative } & \multicolumn{2}{|c|}{ Transformative } \\
\hline & A & B & $\mathrm{C}$ & D & $\mathrm{E}$ & $\mathrm{F}$ & $\mathrm{G}$ & $\mathrm{H}$ \\
\hline Numbers & 48 & 45 & 23 & 9 & 15 & 22 & 37 & 5 \\
\hline$\%$ & $61.53 \%$ & $57.69 \%$ & $29.48 \%$ & $11.54 \%$ & $19.23 \%$ & $28.21 \%$ & $47.44 \%$ & $6.41 \%$ \\
\hline Total & 93 & & 32 & & 37 & & 42 & \\
\hline
\end{tabular}




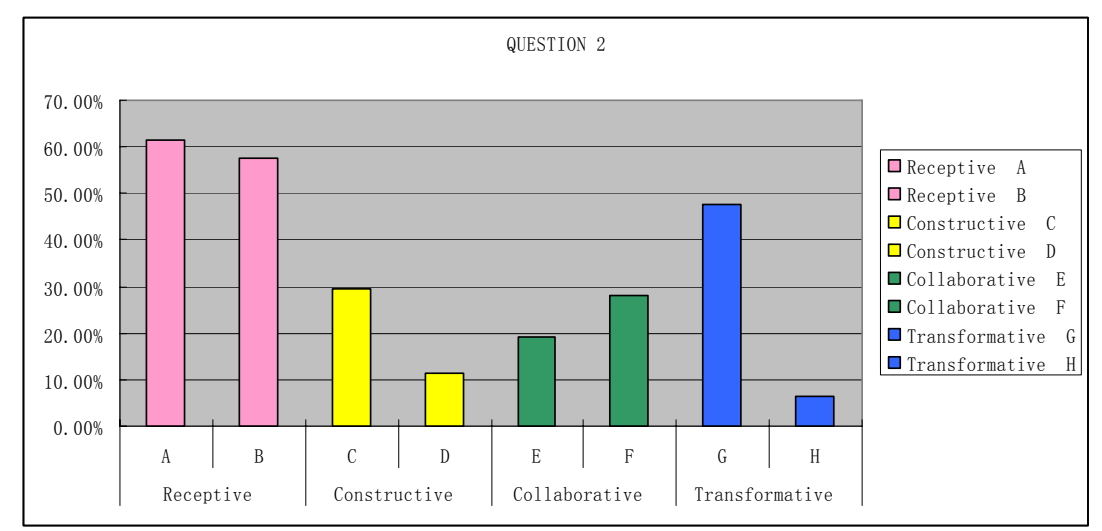

Figure 3. The result of question 2 in bar graph.

Result description: From the Table 3 and Figure 3, we can clearly find that most teachers $(61.53 \%$ and $57.69 \%$ ) deal with listening from receptive perspective, thus we can expect many exercises on checking students' understanding of listening materials are included in such class. Some teachers (47.44\% and 6.41\%) view listening as a process to create a connection between speaker and the listener (transformative perspective), some (19.23\% and $28.21 \%$ ) think it includes negotiation with the speaker (collaborative perspective); and some (29.48\% and $11.54 \%$ ) think it means constructing and representing meaning (constructive perspective). Of all the 78 teachers, 72 teachers choose more than one answer, which proved teachers' comprehensive understanding of the nature of listening.

Question 3: How important do you think listening is?

A: It is important because it is an obligatory course, and because it is indispensible part in all kinds of English tests.

B: It is very important because it serves as an input in language learning, as an access to language acquisition.

C: It is very important because it is an important communicative capacity.

D: Very important because

Table 4

The Results of Question 3 in Table

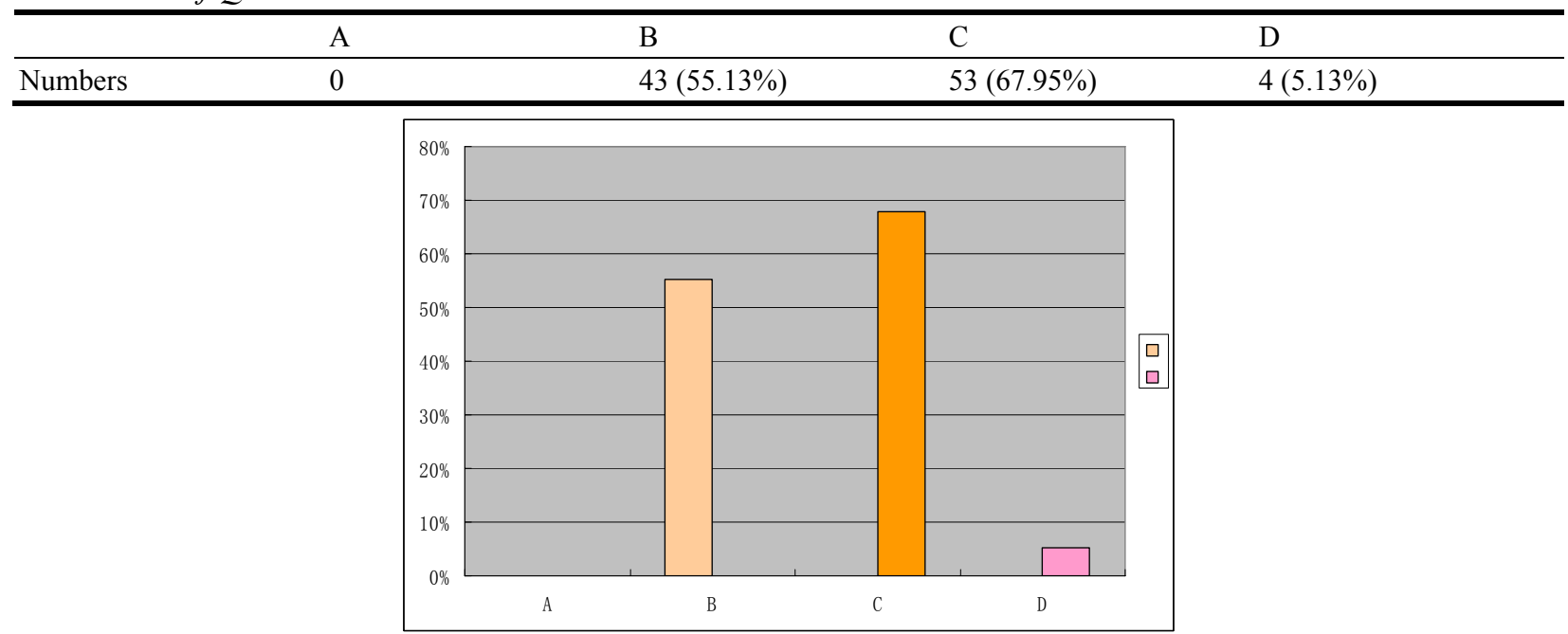

Figure 4. The results of question 5 in bar graph. 
Results description: Question 3 is to investigate the teachers' understanding of the importance of listening, which is influenced by their understanding of listening and will influence their teaching methods in listening class. Among the four choices, nobody choose answer A- "It is important because it is an obligatory course, and because it is indispensible part in all kinds of English tests". This seems like a piece of good news to cheer up the people who are pessimistic about the reality of English education in China - there is no need to worry because our teachers do not teach this course in examination-oriented way. But is the truth really so optimistic? We will wait and see.

From the table, we can see there are almost $68 \%$ of the participants choose $\mathrm{C}$ and $55 \%$ of the participants choose B. These two choices actually reflect the participant preference in communicative approach. As Howatt (1984, p. 279) tells us, the difference between the strong version and the weak version in communicative approach is that: The former entails "using English to learn" while the latter focus on "learning to use". Teachers who choose B- "It is very important because it serves as an input in language learning, as an access to language acquisition"- may put more emphasize on the language capacity, in another words, on the form of language, on the exactness of language. Teachers who choose C- "It is very important because it is an important communicative capacity"-may put more emphasize on the communicative competent rather than on language capacity.

Question 4: What is the main purpose of your listening teaching?

A: To help students get good performance in all kinds of English tests.

B: To teach and make students practice the forms and rules of language.

C: To help students cultivate good listening skills and habits.

D: To help students acquire a communicative capacity to deal with future life and working situations.

Question 4 is to investigate the purpose teachers want to achieve in their listening teaching.

Table 5

Results From Question 4 in Table

\begin{tabular}{lllll}
\hline & A & B & C & D \\
\hline Numbers (\%) & $0(0 \%)$ & $6(7.69 \%)$ & $41(52.56 \%)$ & $50(64.10 \%)$ \\
\hline
\end{tabular}

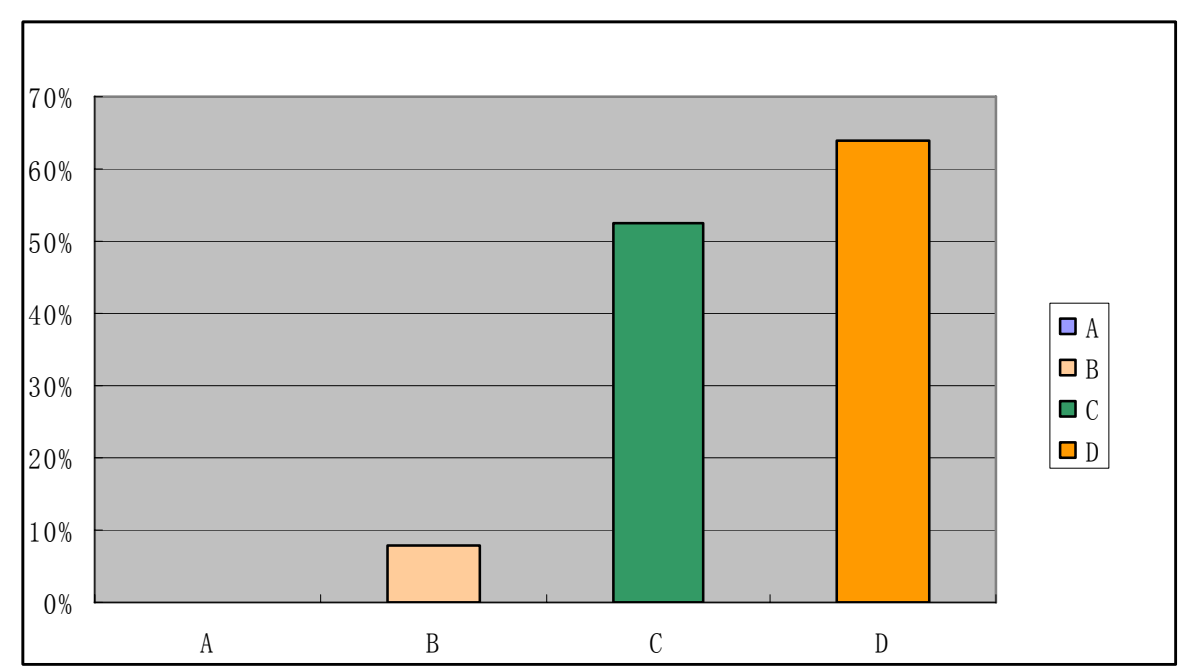

Figure 5. Results from question 4 in graph. 
Result description: Question 4 is to investigate the teachers' purpose of teaching listening. Nobody chooses $\mathrm{A}$, as in the question 3 , because this answer contains very strong connotation of exam-orientation. Compared with $55.13 \%$ of participants choosing B in questions 3, only $7.69 \%$ of the whole choose B in question perhaps because it overtly emphasizes on structuralism, which is form of language. $52.56 \%$ of the participants choosing $\mathrm{C}$ reflects teachers' concern in strategy cultivation. And $64.10 \%$ of participants choosing D reflects teachers' high recognition on communicative approach, which is consistence to the $67.95 \%$ of participants who choose $\mathrm{D}$ in question 3.

Question 5 is to get a feedback of self-evaluation: "Do you think the result of listening teaching has achieved teaching goals?". Of 78 participants, 52 teachers' answer is "Yes", taking $66.66 \%$, while 25 teachers choose "No", which taking $33.34 \%$. The figure is really a surprise to my imagination: One third of teachers do not think the effect of listening teaching achieves the teaching goals. The figure will be more thought-provoking if we consider this question on the basis of the previous analysis: Is there a gap between what we understand about listening and how we teach listening?

\section{Question 6 and Question 12}

According to the study undertaken by Christine C. M. Goh (1997, pp. 124-147), there are 10 problems that occur during listeners' listening process. Half of them are perception problems arising from failure in word recognition and ineffective attention. Three others are problems with parsing and two with utilization. Thus question 6 is designed to find out the teachers' perception of difficulties in students' listening process.

Table 6

Result From Question 6 in Table

\begin{tabular}{llllllll}
\hline & $\mathrm{A}$ & $\mathrm{B}$ & $\mathrm{C}$ & $\mathrm{D}$ & $\mathrm{E}$ & $\mathrm{F}$ & $\mathrm{G}$ \\
\hline \multirow{2}{*}{ Numbers (\%) } & 19 & 27 & 34 & 60 & 43 & 35 & 15 \\
& $24.35 \%$ & $34.62 \%$ & $43.59 \%$ & $76.92 \%$ & $55.13 \%$ & $44.87 \%$ & $19.23 \%$ \\
\hline
\end{tabular}

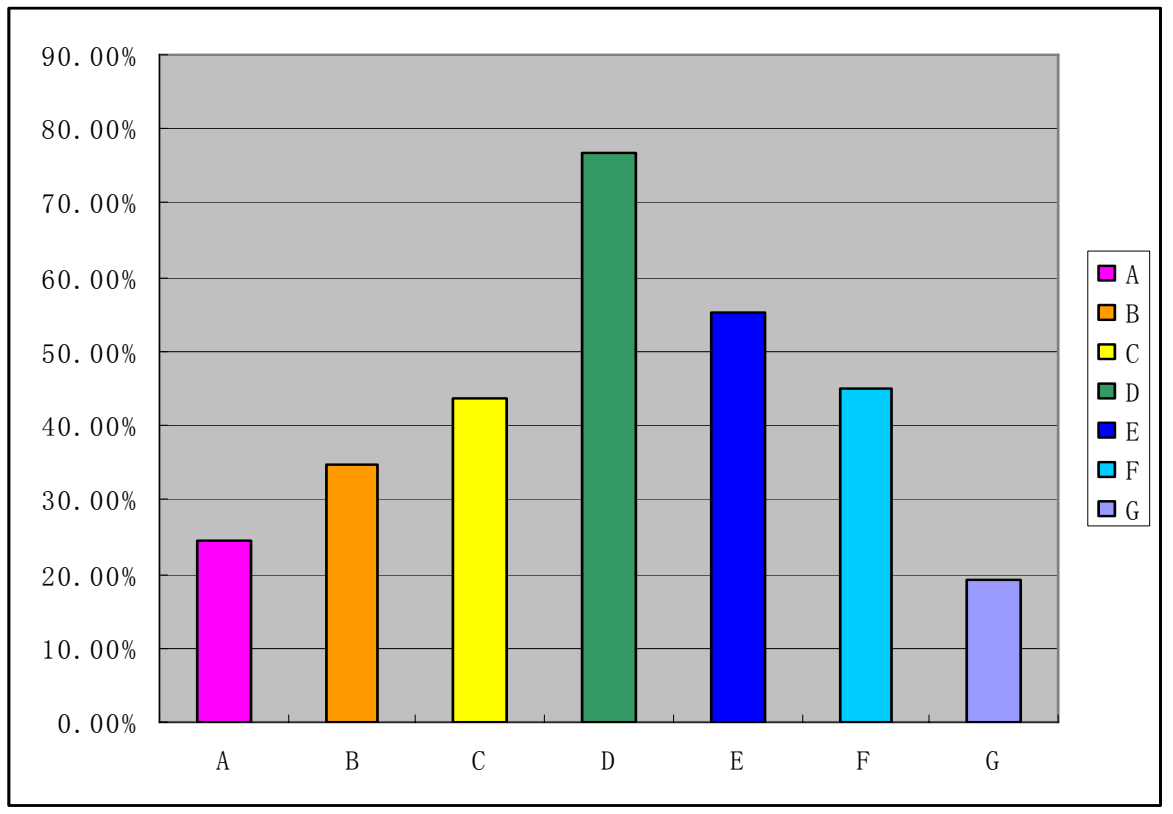

Figure 6. Results from question 6 in bar graph. 
Table 7

Results From Question 12 in Table

\begin{tabular}{llllllllll}
\hline & $\mathrm{A}$ & $\mathrm{B}$ & $\mathrm{C}$ & $\mathrm{D}$ & $\mathrm{E}$ & $\mathrm{F}$ & $\mathrm{G}$ & $\mathrm{H}$ & $\mathrm{I}$ \\
\hline Numbers & 37 & 72 & 42 & 55 & 33 & 9 & 20 & 21 & 30 \\
& $47.44 \%$ & $92.30 \%$ & $53.85 \%$ & $70.51 \%$ & $42.30 \%$ & $11.54 \%$ & $25.64 \%$ & $26.92 \%$ & $38.46 \%$ \\
\hline
\end{tabular}

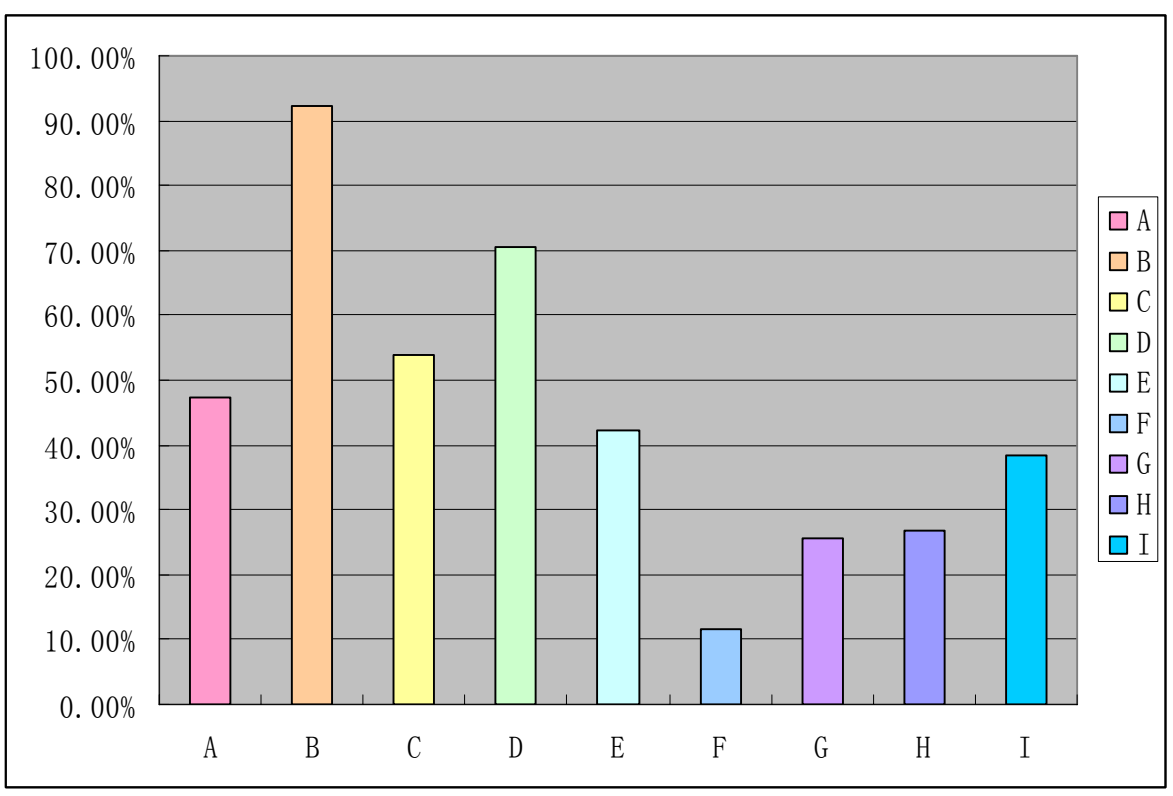

Figure 7. Results from question 12 in bar graph.

Result description: From Table 6, we can see there are about $24.35 \%$ of teachers think the students' main difficulty is A- "they cannot predict the content of listening effectively", which reveals those teachers' understanding of focus on prediction; some $34.62 \%$ of teachers think the difficulty is B- "they cannot figure out the whole information through the given information", which indicates those teachers value the communicative strategy; $43.59 \%$ of teachers think difficulty is C-"they cannot get the main idea of the listening materials", and up to $76.92 \%$ of teachers think the main difficulty is D- "they cannot get detailed information from listening materials", which, according to the previous study on students listening situation, is the most difficult task for them; $55.13 \%$ of the teachers think the difficulty lies in E- "they feel nervous during the listening process", stressing the feeling factor in listening process; $44.87 \%$ of teacher believe that difficulty is because $\mathrm{F}$ - "their attention can be diverted during listening and $19.23 \%$ of teachers think the problem is G- "they cannot take effective notes", the two choices indicating the importance of strategy.

Then what do teachers do to help students solve these problems? Question 12 is designed based the listening strategies_-"What strategies you have taught in listening class?". From Table 7 and Figure 7, 47.44\% of teachers choose A- "how to take notes", a basic strategy students may have less difficulty with (you can see from above). Up to $92.30 \%$ of teachers taught the strategy of how to predict (B), though we can see from above the effect are not very good. More than half of teachers taught how to get main idea of the listening materials (C), and more than $70 \%$ of teachers taught how to get detailed information (D); however, these are two strategies students having most difficulty with. $42.30 \%$ of teachers taught how to identify the varied difference of information (E) and $11.54 \%$ of teachers taught how to solve the problem of insufficient understanding (F). 
$25.64 \%$ of teachers taught how to get information from body language and facial expressions $(\mathrm{G})$, and $26.92 \%$ of teachers taught how to negotiate with the speaker about the information $(\mathrm{H})$, two of which are capacities in communicative capacity. $38.46 \%$ of teachers taught how to conduct strategy analysis before listening (I).

\section{Question 7 to Question 11}

Question 7 and question 8 are mainly concern about the listening materials adopted in class teaching, which is one of the factors contributing to the difficulty in students' listening. The results are presented in table and in graph.

Table 8

Results From Question 7

\begin{tabular}{lllll}
\hline $\mathrm{A}$ & $\mathrm{B}$ & $\mathrm{C}$ & $\mathrm{D}$ & $\mathrm{E}$ \\
\hline 77 & 71 & 76 & 21 & 12 \\
$98.72 \%$ & $91.02 \%$ & $97.43 \%$ & $25.92 \%$ & $15.38 \%$ \\
\hline
\end{tabular}

Result description: From the Table 8, you can see clearly that most teacher adopt textbook as their teaching materials, which is often the course requirement. Up to $97.43 \%$ of teachers use the materials from internet or radio to give live English, and $91.02 \%$ of teachers use movie to provide language input and to arouse interest of students. The teachers who use authentic language materials and language from other resource are comparatively fewer (only $25.92 \%$ and $15.38 \%$ ).

Then how does the teacher think of the difficulty degree of the listening materials? Table 9 gives detail on it.

Table 9

Results From Question 8

\begin{tabular}{|l|l|}
\hline A: Very difficult & $8(10.25 \%)$ \\
\hline B: A little difficult & $70(89.74 \%)$ \\
\hline C: Not difficult & $3(3.8 \%)$ \\
\hline D: Easy & $0(0 \%)$ \\
\hline
\end{tabular}

Result description: From the table above, we can see most teachers think the materials are a little difficult to the students' level, which they believe is beneficial for listening learning. $10.25 \%$ of the teachers think the materials are very difficult to students' level, which may de-motivate students. Nobody think the materials are easy.

Question 9 to question 11 mainly focus on the activities teachers conduct in class teaching. The following tables and figures reveal the results of these questions.

Table 10

Results From Question 9

\begin{tabular}{lllllll}
\hline & $\mathrm{A}$ & $\mathrm{B}$ & $\mathrm{C}$ & $\mathrm{D}$ & $\mathrm{E}$ & $\mathrm{F}$ \\
\hline Numbers & 50 & 65 & 8 & 37 & 1 & 1 \\
$(\%)$ & $64.10 \%$ & $83.33 \%$ & $10.26 \%$ & $47.43 \%$ & $1.28 \%$ & $1.28 * \%$ \\
\hline
\end{tabular}

From Table 10, we find $83.33 \%$ of the teachers adopt group activities and group discussion as the main methods in class teaching, and $64.10 \%$ of the teachers mainly play the listening materials and check the answers. $47.43 \%$ of the teachers will use video tools to teach. These three kinds of activities consist of the main part of teachers class teaching.

Then, in question 10, the per-listening activities are concerned. Table 11 will illustrate the results. 
Table 11

Results From Question 10

\begin{tabular}{|l|l|}
\hline A: Explain the words and phrases in listening materials & $51(65.38 \%)$ \\
\hline B: Present the topic-related picture and background information & $57(73.07 \%)$ \\
\hline C: Let the students predict what they will hear & $36(46.15 \%)$ \\
\hline D: Conduct topic-related discussion & $65(83.33 \%)$ \\
\hline E: Read topic-related passages & $2(2.56 \%)$ \\
\hline F: Make students answer topic-related questions & $32(41.03 \%)$ \\
\hline G: Explain the grammar and syntax in listening materials & $18(23.07 \%)$ \\
\hline H: Do nothing & $5(6.41 \%)$ \\
\hline
\end{tabular}

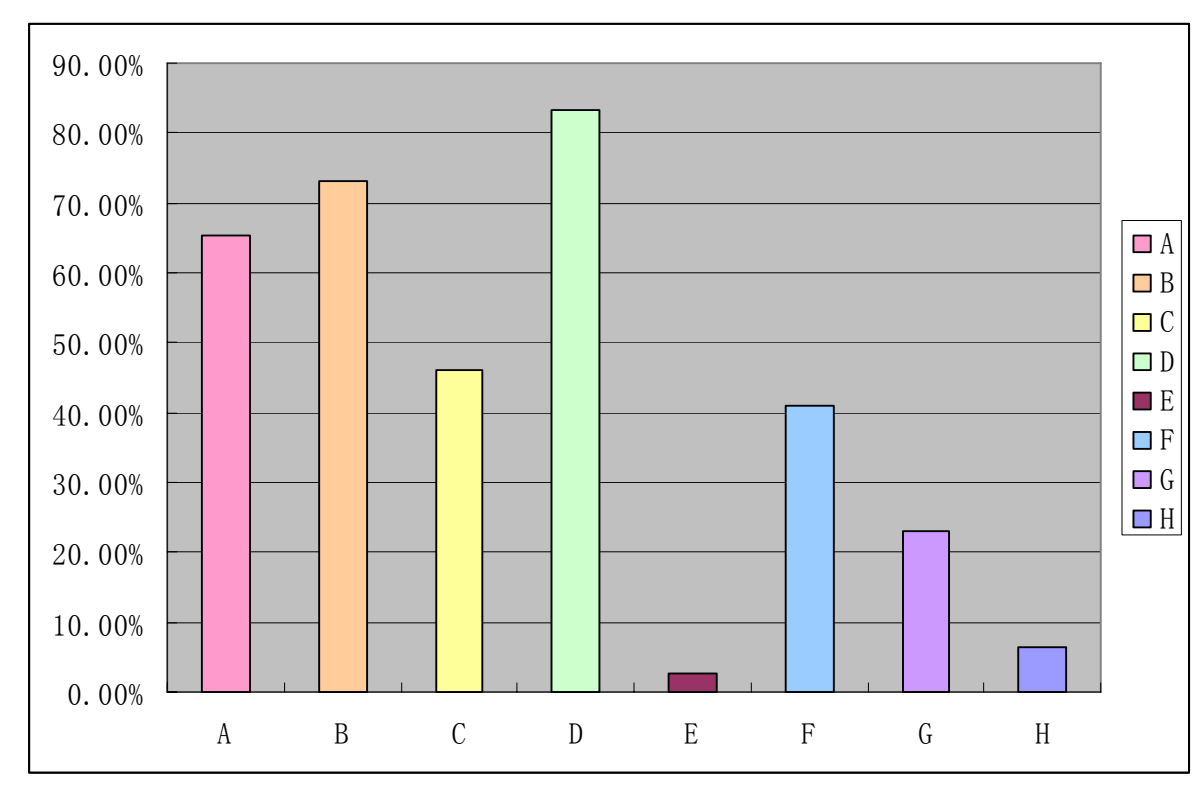

Figure 8. Results from question 10 in bar graph.

Result description: From the table and figure above, we can see that teacher favor the activity of group discussion most $(83.33 \%)$. The second favorite activity among teachers is to present the topic-related picture and background information (73.07\%). The other favorite activities are explaining the words and phrases in listening materials $(65.38 \%)$, making students predict what they will hear $(46.15 \%)$, and making students answer topic-related questions (41.03\%). Some teachers may explain grammar and syntax in the listening materials $(23.07 \%)$, but a very few teachers will make students read topic-related passages $(2.56 \%)$ or do nothing $5(6.41 \%)$.

Question 11 is concerning about the exercise teachers use during the while-listening stage.

Table 12

Results From Question 11

\begin{tabular}{|l|l|}
\hline A: Multiple-choice exercise & $51(65.38 \%)$ \\
\hline B: Information gap, jigsaw & $37(47.44 \%)$ \\
\hline C: Fill in the blanks with phrases and words & $48(61.54 \%)$ \\
\hline D: Answer the questions & $40(51.28 \%)$ \\
\hline E: Fill in the table & $23(29.49 \%)$ \\
\hline F: Draw a picture & $13(16.67 \%)$ \\
\hline G: Other exercises & $14(17.95 \%)$ \\
\hline
\end{tabular}




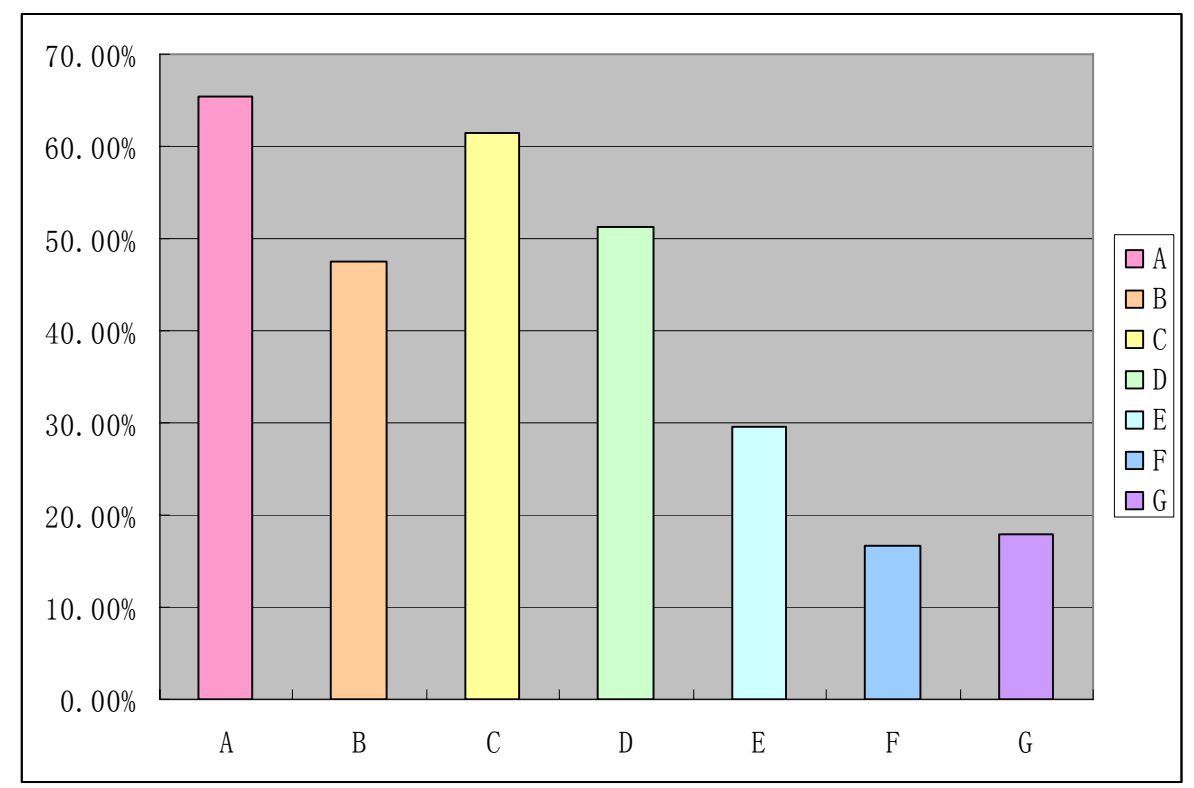

Figure 9. Results from question 11 in bar graph.

Results description: From the table and bar graph, we can see that most teacher choose some traditional exercises, such as multiple-choices-question and answering the question, as the main measures to check the effect of students' listening ability and listening learning, forgetting that class teaching should not be equal to a test. There are some teachers choose communicative approach to conduct their class teaching: Nearly half of the teachers choose information gap and jigsaw as the listening exercise. However, by interviewing with the teachers who choose B, I found that some of them even do not know what is information gap or jigsaw. So the comparatively high statistic in this choice is of low validity.

\section{Conclusion}

When the theory of listening is concerned, most teachers have recognized the importance of listening, and have cultivated a communicative perspective for how to teach listening. However, when the concrete activities are concerned, many teachers still adopt the traditional PPP approach, that is, Presentation, Practice, and Production. The results have revealed roughly the current conditions concerning listening teaching and learning in universities of China. Some problems and disadvantages have been exposed. Finding out the disadvantages and problems is only the beginning, and next important step is to find out solutions and changes in class teaching. This is awaiting further research and study on the teaching methods and practice.

\section{References}

Goh, C. (1997). Metacognitive awareness and second language listener. ELT Journal, 51(4), 361-369.

Howatt, A. P. R. (1984). A history of English language teaching. Oxford: Oxford University Press.

Mendelsohn, D. (1998). Teaching listening. In W. Grabe (Ed.), Annual review of applied linguistics: Foundations of second language teaching (p. 18). Cambridge: Cambridge University Press.

Rost, M. (1991). Listening in action. Englewood Cliffs, N.J.: Prentice Hall.

Rost, M. (2005). Teaching and researching listening. Beijing: Beijing Foreign Language Teaching and Research Press. 